\title{
Technology and experimental studies of contacts for microwave diodes based on interstitial phases
}

\author{
N.S. Boltovets', V.N. Ivanov'1, R.V. Konakova², A.M. Kurakin², V.V. Milenin ${ }^{2}$, \\ E.A. Soloviev ${ }^{2}$, G.M. Verimeychenko ${ }^{1}$

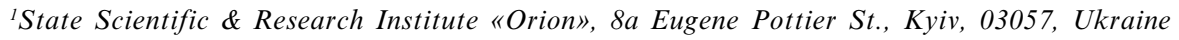 \\ Tel./Fax: (380-44) 456-05-48; E-mail:bms@i.kiev.ua \\ ${ }^{2}$ Institute of Semiconductor Physics, NAS Ukraine, 45 Prospect Nauki, Kyiv, 03028, Ukraine \\ Tel.: (380-44) 265-61-82; Fax: (380-44) 265-83-42; E-mail: konakova@eee.semicond.kiev.ua
}

\begin{abstract}
We consider some aspects of manufacturing technology for films of refractory metals nitrides and borides. These films are used for barrier and ohmic contacts, as well as contacts with antidiffusion layers, in gallium arsenide and silicon epitaxial structures that are used to produce microwave diodes. We investigated the properties of sputtered films and metal-semiconductor interfaces, as well as electrophysical parameters of contact structures and IMPATT diodes. The contact structures based on titanium borides and nitrides and zirconium borides are shown to have high thermal stability.
\end{abstract}

Keywords: thin $\mathrm{TiB}_{x}$ films, thin $\mathrm{TiN}_{x}$ films, thin $\mathrm{ZrB}_{x}$ films, thin $\mathrm{NbN}_{x}$ films, rapid thermal annealing, contact structure, microwave diode, reliability of IMPATT diodes.

Paper received 19.01.01; revised manuscript received 31.01.01; accepted for publication 16.02.01.

\section{Introduction}

It is known that metal-semiconductor contacts must provide, during the device service life, minimal mass transport on the outside of contact system (that includes gold and copper), as well as that of semiconductor structure components to the external device elements. This may be achieved when forming a barrier layer of quasi-amorphous structure; such layer should remain stable during both technological cycle of diode manufacturing and longterm diode operation [1-4].

The near-contact regions and barrier layers are key elements for providing thermal stability and long-term service life of diodes. That is why our investigations have been focused mainly on the features of technological processes used in formation of barrier layers and metal-semiconductor interfaces, as well as on how the characteristics of contacts obtained depend on heat and radiation actions.

2. Some features of the technological process used in preparation of $\mathrm{TiB}_{x}, \mathrm{TiN}_{x}, \mathrm{NbN}_{x}$ and $\mathrm{ZrB}_{\boldsymbol{x}}$ films

We studied different technological techniques for barrier layer formation, namely, (i) magnetron sputtering of targets (formed by stoichiometric compounds - borides $\mathrm{TiB}_{2}$, $\mathrm{ZrB}_{2}$ and nitrides $\mathrm{TiN}, \mathrm{NbN}$ ), (ii) thermal reactive mag- netron sputtering of targets in a mixture of nitrogen and argon, and (iii) thermionic synthesis of nitrides.

For magnetron sputtering we used targets made of stoichiometric powder materials using methods of powder metallurgy. The magnetron design enabled us also to use targets as coarse-grained powder.

The studies of technological way with magnetron sputtering were performed using a technological set equipped with four magnetrons of unique design. The target diameter was $60 \mathrm{~mm}$. A diagram of magnetron is presented in Fig.1. The magnetron design enabled us to use both solid targets and those as powders of a pre-synthesized compound. Presence of four magnetrons in a reactor chamber made it possible to prepare composite contact systems during a single technological cycle.

The reactor chamber with magnetrons was evacuated using a turbo-molecular pump with nitrogen freezingout system; the residual pressure was $7 \times 10^{-4} \mathrm{~Pa}$. Precision leak-in of argon and nitrogen was performed using a unique two-chamber system. The pressure in the chamber during sputtering was $0.7 \mathrm{~Pa}$. We investigated technological procedures in the $0.2-1.4$ A range of magnetron discharge current. The layer growth rate was adjusted within the 0.2 to $2 \mathrm{~nm} / \mathrm{s}$ range.

Thermionic synthesis of TiN layers was performed using a specially equipped technological plant (see Fig. 2). It operated in a self-maintained arc discharge in the sputtered material vapor. 
N.S. Boltovets et al.: Technology and experimental studies of contacts for ...

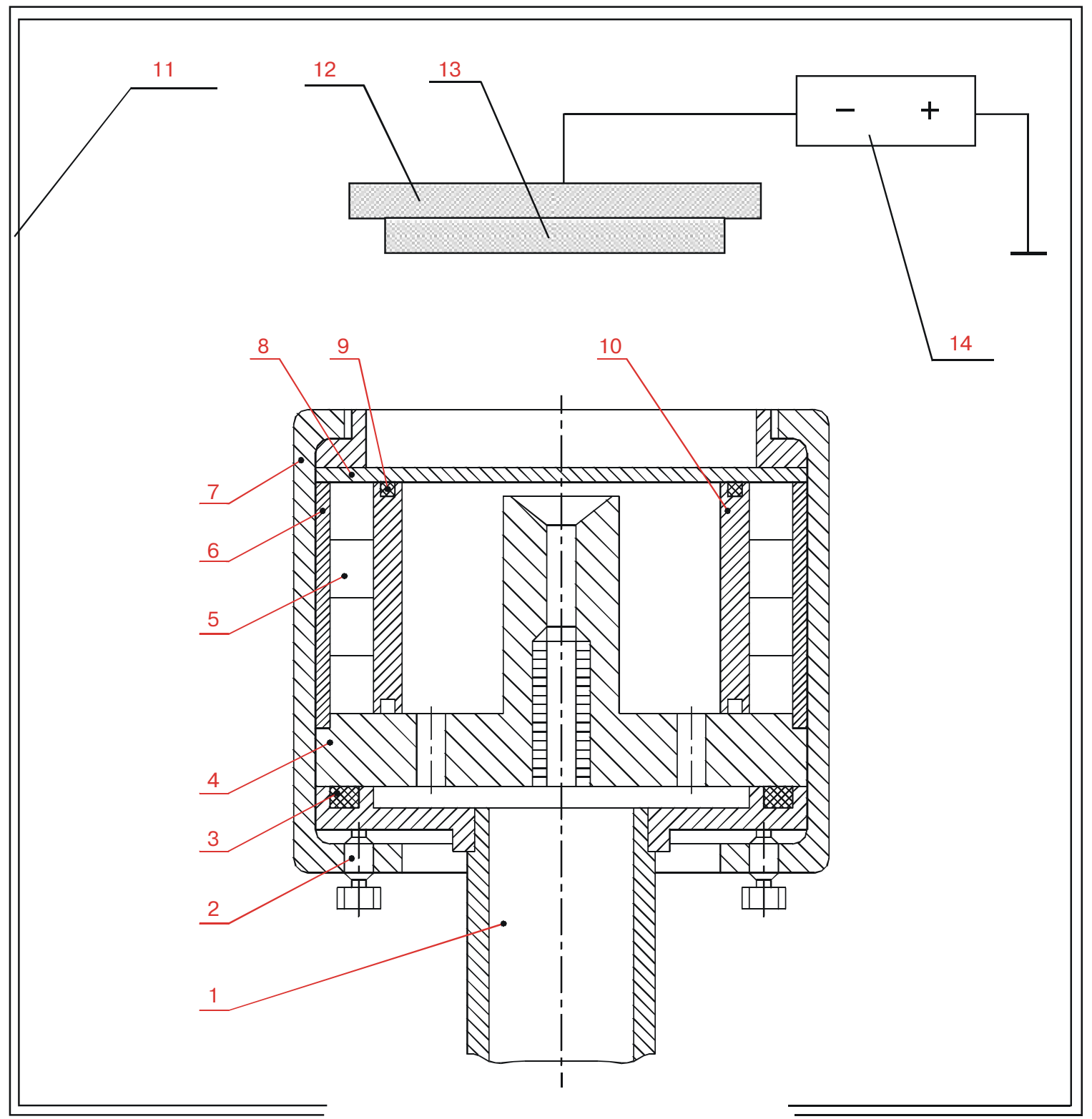

Fig. 1. Diagram of the magnetron technological equipment: 1 - water supply system; 2 - screw; 3 - gasket; 4 - magnetic circuit; 5 magnet; 6 - barrel; 7 - hood; 8 - target; 9 - gasket; 10 - bushing; 11 - vacuum chamber; 12 - holder; 13 - substrate; 14 - system for potential supply.

The metal vapor was ionized in crossed magnetic and electric fields. The degree of layer ionization was $10-20 \%$; the pressure in the reactor chamber was $2 \times 10^{-2} \mathrm{~Pa}$. Concurrent with the ionized metal vapor, a supersonic nitrogen flow was supplied to the substrate. This provided synthesis and deposition of metal nitrides onto the substrate. The equipment enabled us to obtain compound layers 0.05 to $10 \mu \mathrm{m}$ thick. Presence of ionized plasma and possibility to apply control potentials to the substrate enabled us to control the structure, thermo-mechanical and adhesion characteristics of nitride layers on the substrate. The equipment made it possible to form highly stable layers at voltages and arc discharge currents $60-80 \mathrm{~V}$ and 35-40
A, respectively. The ion current to the substrate was $0.1-$ $0.2 \mathrm{~A}$. The accelerating potential applied to the substrate could be down to $-260 \mathrm{~V}$. The deposition rate under the above conditions was $0.1 \mu \mathrm{m} / \mathrm{min}$.

Taking into account that the contact systems studied were complicated and multivariant, we investigated first the barrier layer and barrier layer-semiconductor interface, and then the near-contact region with a heavily doped recrystallized layer. Contact systems for complex investigations have been chosen after a preliminary analysis.

Concurrent with this, we studied possibilities to combine the manufacturing technology for contact system with technological cycle of the diode mesa formation. The prob- 
N.S. Boltovets et al.: Technology and experimental studies of contacts for ...

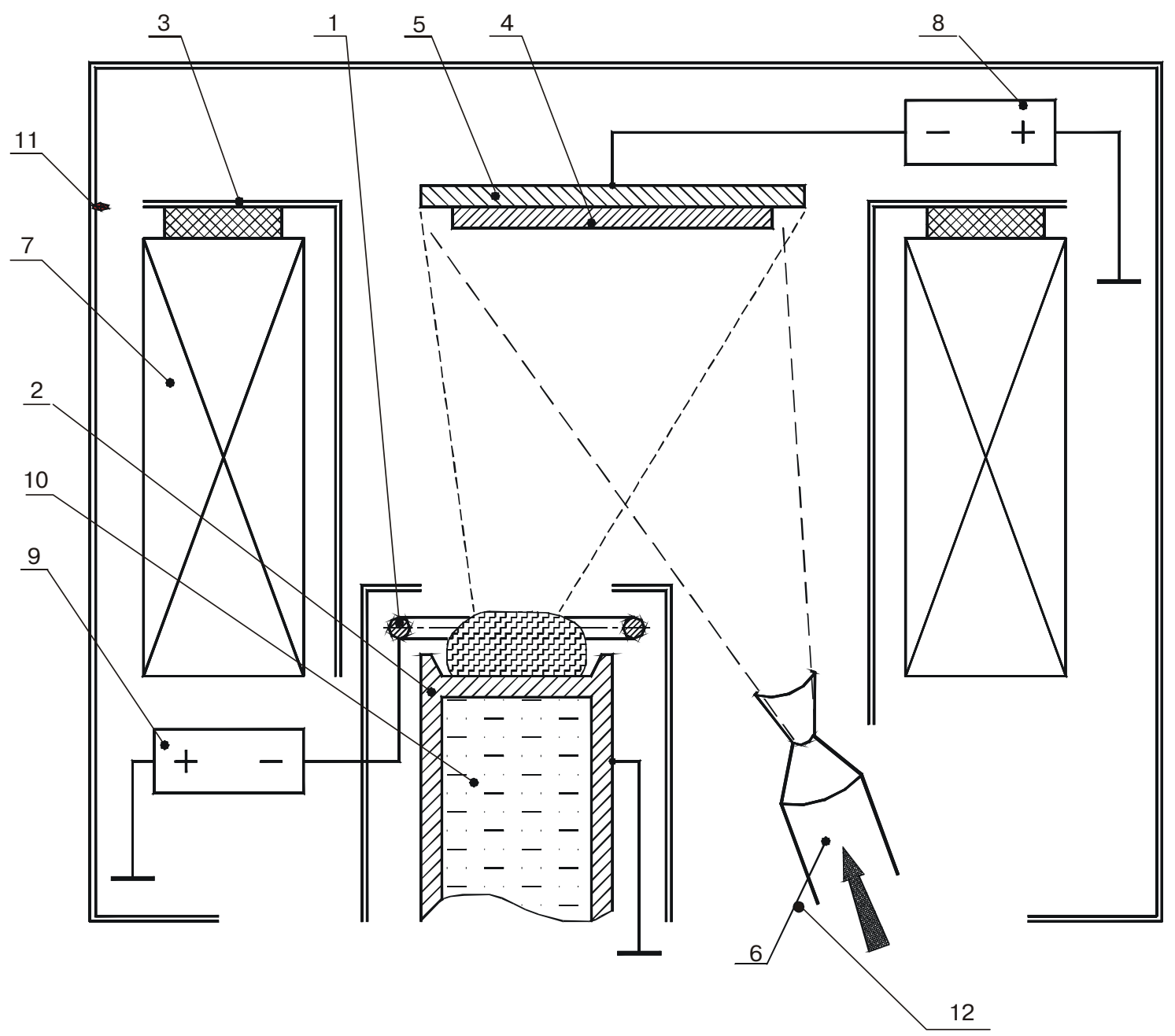

Fig. 2. Diagram of thermal ionic technological equipment: 1 - cathode; 2 - anode; 3 - screen; 4 - substrate; 5 - holder; 6 - system for gas mixture supply; 7 - magnet; 8- system for potential supply; 9 - discharge supply system; 10 - water cooling system; 11 - vacuum chamber.

lem of such combination is that a mesa $30-100 \mu \mathrm{m}$ in diameter is formed by etching a semiconductor layer to a depth of 10-30 $\mu \mathrm{m}$. When etching mesa, no etch undercut of the contact system components should occur, since such etch undercut drastically impairs the thermal and electrical characteristics of diode structures.

We investigated structure, phase and elemental compositions of both barrier layers in the contact systems and the barrier layer-semiconductor interface, as well as how these characteristics depend on the formation methods and modes and how they change under heating and $\gamma$-radiation.

The magnetron sputtering technology provides a rather wide range of sputtering rates when standard magnetron discharge modes are used. Our structural investigations of thin $(10-30 \mathrm{~nm})$ barrier layers with scanning electron microscope (SEM) in the transmission mode have shown that amorphous structure is formed at rather low $(0.2-0.6 \mathrm{~nm} / \mathrm{s})$ deposition rates. When the sputtering rate grew to $0.6-1.0 \mathrm{~nm} / \mathrm{s}$, then polycrystalline films were formed. A typical SEM pattern for $\mathrm{ZrB}_{x}$ polycrystalline film is shown in Fig. 3.

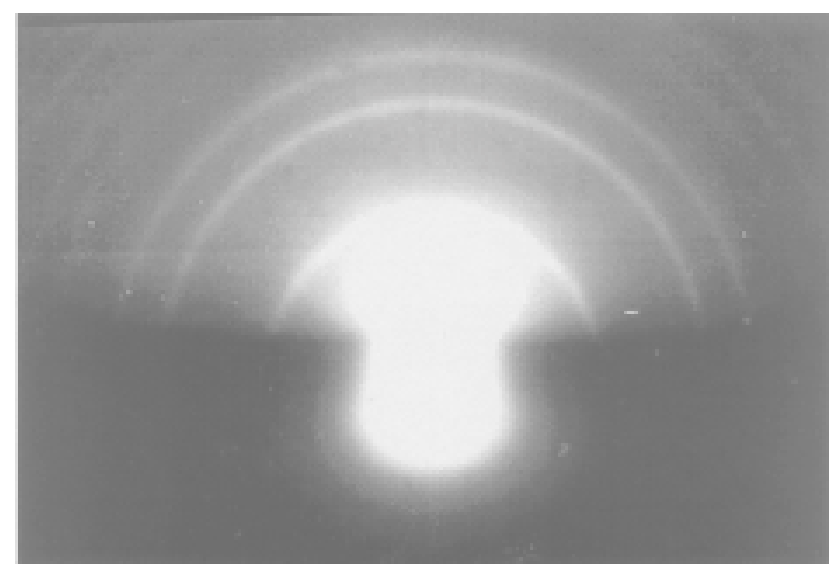

Fig. 3. SEM patterns of $\mathrm{ZrB}_{x}$ layers. 


\section{N.S. Boltovets et al.: Technology and experimental studies of contacts for ...}

It should be noted that use of transmission mode enables one to check the barrier layer structure at the initial stages of layer formation. The total thickness of barrier layers used at contact formation was as big as 100$200 \mathrm{~nm}$. To study the barrier layers of such thicknesses, we used SEM in the reflection mode. The angle of electron beam incidence (reflection) relative to the surface was taken from the 3 to $10^{\circ}$ range.

SEM patterns obtained in the above way give integral information on the surface structure of a barrier layer 5-10 nm thick (see Figs 4, 5). One can see reflection spots on the SEM patterns for barrier layers obtained using magnetron and thermionic methods. These spots are characteristic of a fine-crystalline phase with some fraction of an amorphous phase. In the near-surface layer the barrier is of a quasi-amorphous structure. The latter is an amorphous matrix with crystallites of the dominant phase. Our structural investigations have shown that the barrier layers formed at low sputtering rates are an amorphous matrix where crystallites of sizes from 3 to $15 \mathrm{~nm}$ may be present.

We would like to stress that the results obtained for a thin near-surface layer may be applied to estimate the state of the whole barrier only with some reservations.

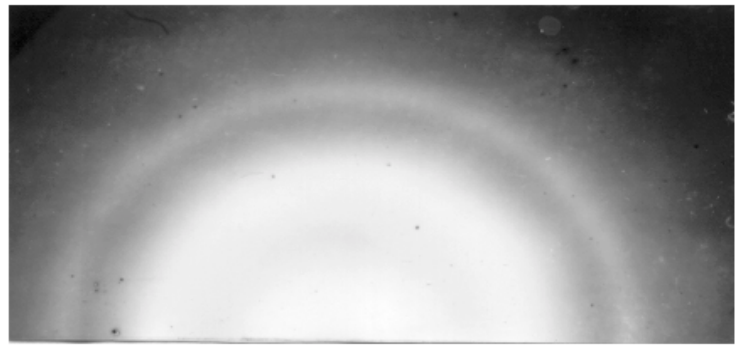

a)

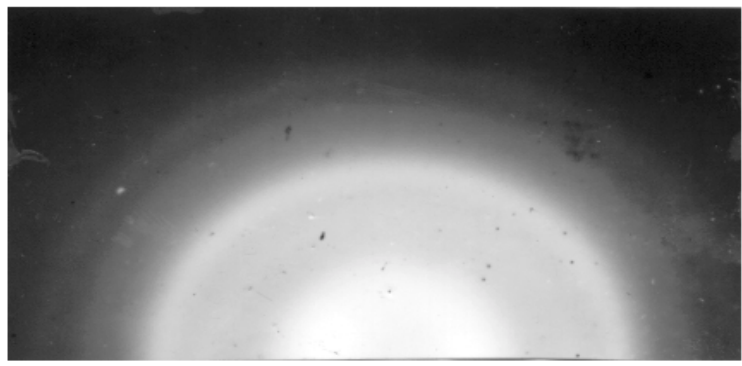

b)

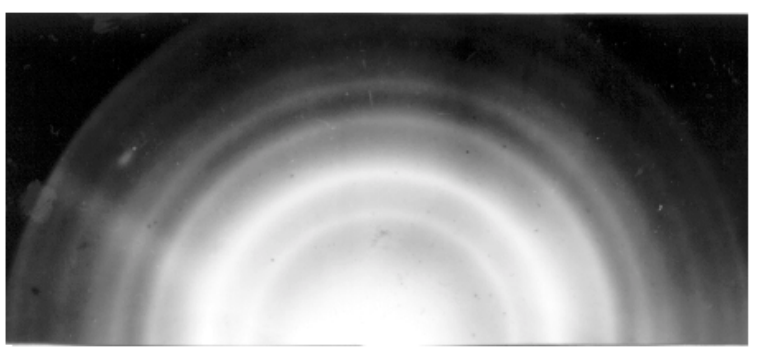

c)

Fig.4. SEM patterns of $\mathrm{TiB}_{x}$ layers taken in different discharge modes: discharge current $0.2 \mathrm{~A}$ (a), $0.4 \mathrm{~A}$ (b), $1.0 \mathrm{~A}$ (c).

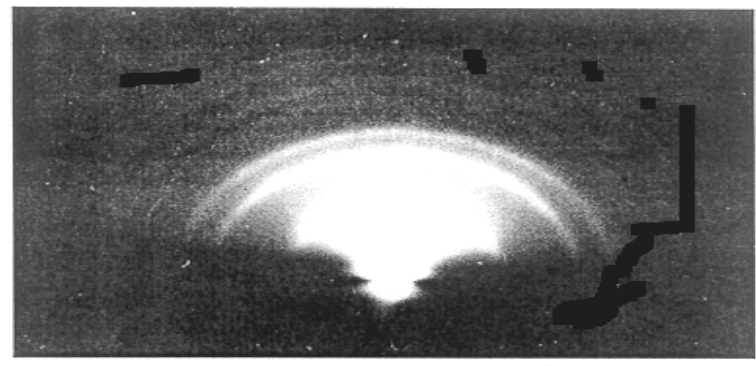

b)

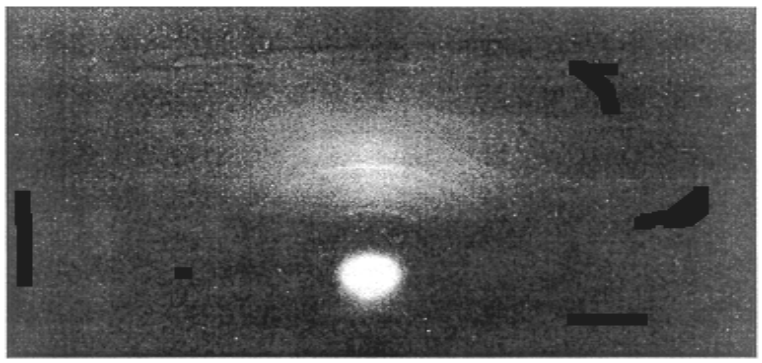

c)

\section{Effect of rapid thermal annealing on the parameters of $\mathrm{TiB}_{x}, \mathrm{TiN}_{x}$ and $\mathrm{ZrB}_{x}$ layers and contacts based on them}

We studied thermal stability of both elemental and phase composition of barrier layers and barrier layer (boride, nitride)-semiconductor (silicon, gallium arsenide) interfaces. For this test, structures were made with compound layers whose thickness was about $50 \mathrm{~nm}$. The test structures were studied before and after rapid (10-60 s) thermal annealing (RTA) in hydrogen atmosphere at temperatures $T=400,600,800,900$ and $950{ }^{\circ} \mathrm{C}$. The distribution of the elemental and phase composition in depth of barrier layers was investigated using Auger electron spectroscopy (AES) and X-ray photoelectron spectroscopy (XPS) with layer-by-layer ion etching of a contact system from its surface to the metal-semiconductor interface. To study layer morphology, we used electron microscopy.

RTA simulates, to a first approximation, a pulse overload that might occur during long-term operation of diode structures. In addition, «rapid» isochronous annealing enables one to make comparative estimation of thermal stability for contact systems. The thickness range for transition layers used in simulation studies was also de-

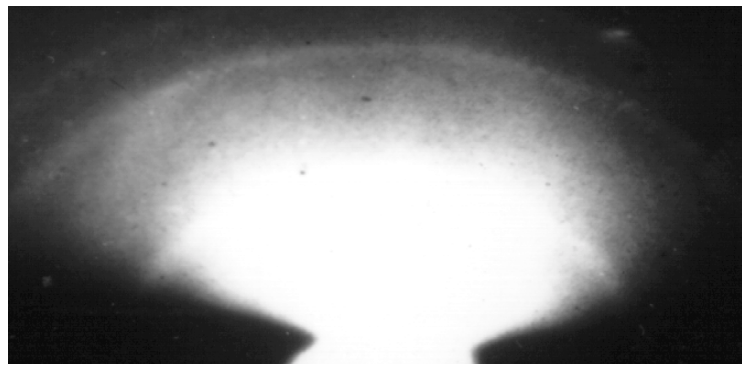

a)

Fig. 5. SEM patterns of $\mathrm{TiN}_{x}$ layers prepared in different ways: a (b) - magnetron sputtering, deposition rate $0.5(1.0) \mathrm{nm} / \mathrm{s}$; c thermionic sputtering, deposition rate $100 \mathrm{~nm} / \mathrm{s}$. 


\section{N.S. Boltovets et al.: Technology and experimental studies of contacts for ...}

termined by potentialities of analytical instruments, and real time required for the layer-by-layer analysis of contact systems.

XPS studies of gallium arsenide surface have shown that, after chemical treatment and washing in deionized water, the dominant phases at GaAs surface are $\mathrm{Ga}_{2} \mathrm{O}_{3}$ (binding energy of Ga $2 p_{3 / 2}$-electrons $\left.E_{b} \approx 1118.4-1118.9 \mathrm{eV}\right)$, $\operatorname{arsenic}\left(E_{b} \approx 40.7-41.6 \mathrm{eV}\right)$ and $\operatorname{arsenic}$ oxide $\left(E_{b} \approx 44.2 \mathrm{eV}\right)$. The ratio between $\mathrm{Ga}$ and As concentrations $(\approx 0.9)$ is below the stoichiometric one; the oxygen content in the near-surface layer ( $2 \mathrm{~nm}$ thick) amounts up to 10 at.\%.

To clean gallium arsenide surface, we have developed and applied a technique of pulse photon cleaning. The GaAs wafers were cleaned directly in the reactor chamber before deposition of the first layer of contact system.

Our investigations of the barrier layers based on titanium nitrides ( $\mathrm{TiN}_{x}$-GaAs) have proved their high thermal stability up to temperatures of about $600^{\circ} \mathrm{C}$. At temperatures from 400 to $600{ }^{\circ} \mathrm{C}$ component redistribution was observed. It was due to formation of $\mathrm{GaAs}_{x} \mathrm{~N}_{1-x}$ solid solution at the metal-semiconductor interface. RTA at temperatures about $600{ }^{\circ} \mathrm{C}$ resulted in homogenization and formation of phases of variable composition.

An analysis of the results of studies of borides on gallium arsenide ( $\mathrm{TiB}_{x}$-GaAs) has shown that barrier layers remained stable up to a temperature of $600^{\circ} \mathrm{C}$. Starting from $T=400^{\circ} \mathrm{C}$, an interlayer of a solid solution of variable composition $\left(\mathrm{Ga}_{x} \mathrm{~B}_{1-x} \mathrm{As}\right)$ began to form at the $\mathrm{TiB}_{x^{-}}$ GaAs interface. Such an interface composition provided an additional thermal stability over some temperature range. During RTA the layer becomes more homogeneous. Chemical bonds that are characteristic of $\mathrm{TiB}_{x}$ are predominant. RTA at $T=800{ }^{\circ} \mathrm{C}$ results in smearing out of the layered structure and phase intermixing over the barrier layer.

The boride $\left(\mathrm{TiB}_{x}, \mathrm{ZrB}_{x}\right)$ barrier layers on silicon remain stable at temperatures over $600^{\circ} \mathrm{C}$. Shown in Fig. 6 are typical results of a layer-by-layer analysis of the Si$\mathrm{ZrB}_{x}$ system. One can see from the concentration depth profiles that a phase is being formed enriched with the metal. The process of the film condensate formation is accompanied by movement of the film-substrate interfaces. One may suppose that silicon interaction with the film components serves as chemical reactions that determine formation of a transition layer when depositing $\mathrm{ZrB}_{x}$. These reactions lead to a disruption of the semiconductor near-surface layer accompanied by formation of phases of variable composition.

Our investigations of changes in binding energies of $\mathrm{Zr} 3 d_{5 / 2}$-and $\mathrm{B} 1 s$-electrons and comparison between them and binding energies of core electrons enabled us to draw some conclusions concerning phase composition of the sputtered layers. The chemical state of zirconium atoms is determined by two coordinations whose binding energies for $3 d_{5 / 2}$-electrons lie within the 180.0-180.5 and $182.0-183.0 \mathrm{eV}$. The first of these states is characteristic of zirconium borides, while the second one - of oxyborides. This conclusion is supported also by changes in the binding energies of $1 s$-electrons. Thus the sputtered layer is a mixture of two phases whose fractions vary in depth.
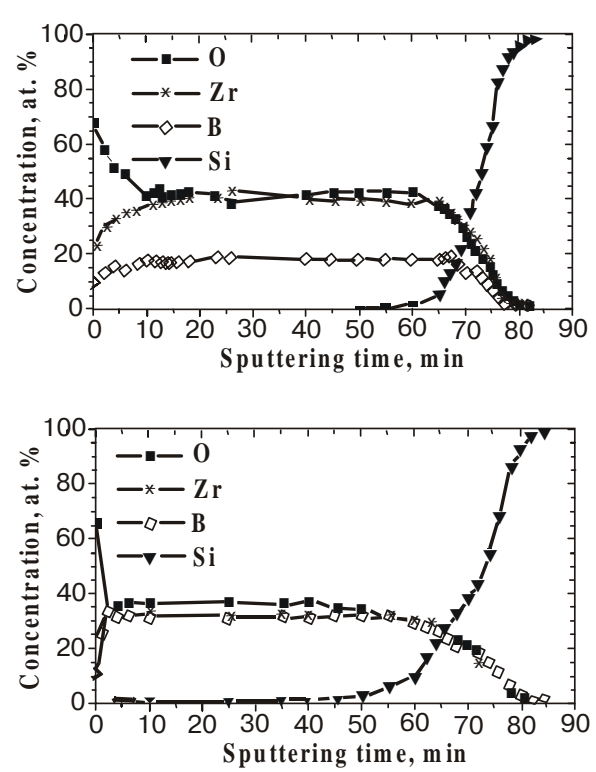

b)

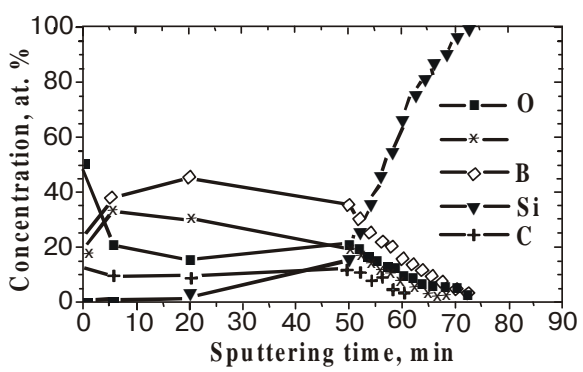

c)

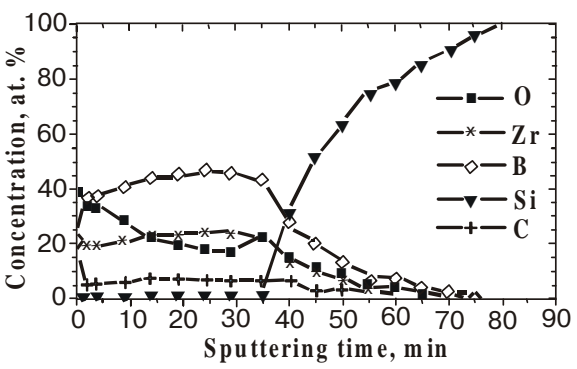

d)

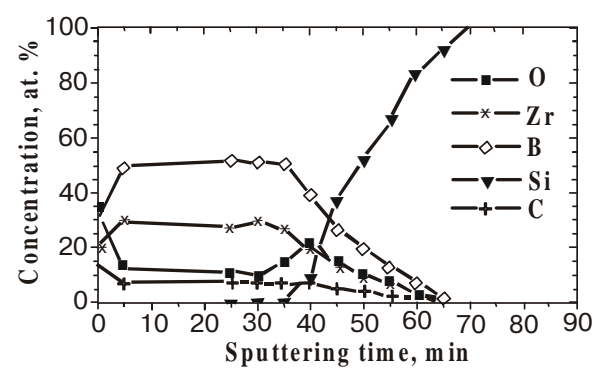

e)

Fig. 6. Concentration depth profiles for the $\mathrm{ZrB}_{x}-\mathrm{Si}$ contact components: a - initial (before annealing) sample; b, c, d, e - after RTA at $T=400,600,800,950{ }^{\circ} \mathrm{C}$. 


\section{N.S. Boltovets et al.: Technology and experimental studies of contacts for ...}

RTA at $400{ }^{\circ} \mathrm{C}$ is accompanied by a structural phase transition in the sputtered film. This transition is due to zirconium monoboride formation. Structural relaxation in the sputtered layer that is stimulated by RTA makes the transition layer wider and reduces its chemical inhomogeneity.

High-temperature RTA increases structural-phase non-uniformity of both the sputtered film and contact transition layer at $800-950{ }^{\circ} \mathrm{C}$. This seems to be due to proceeding of a competing reaction between silicon atoms and film components. One may think that under these conditions processes of silicides and silicates formation are enhanced. This is the physico-chemical basis of hightemperature degradation of the contact systems studied.

Nitride $\left(\mathrm{TiN}_{x}\right)$ barrier layers on silicon that were formed using magnetron sputtering are rather stable up to temperatures of about $600-800^{\circ} \mathrm{C}$. During deposition of the titanium nitride film $\mathrm{Ti}$ and $\mathrm{N}$ atoms are penetrating deep into the substrate. This fact, along with excess nitrogen and oxygen in the film, seem to determine thermal stability of the barrier layer. Those atoms that entered the semiconductor form (with its matrix) disordered solid solutions. Presence of excess oxygen in the films indicates at considerable oxidation of powder targets. Oxygen impurities and competing character of Ti-Si and Ti-O bonding strongly affect the character of phase transformations.

The titanium nitride layers obtained using thermionic reactive synthesis are characterized by higher phase and electrical uniformity and contain small (2-3\%) oxygen and carbon concentrations.

Morphological studies of metallization layers when varying composition of the contact multilayer structure and annealing temperature enable one not only to make estimations of threshold values of their thermal stability but to draw some conclusions concerning the reasons for their degradation under heating as well.

Shown in Fig. 7 are the results of our SEM studies of film structures obtained using magnetron sputtering onto different semiconductor substrates. The samples were exposed to RTA at a temperature of $800^{\circ} \mathrm{C}$. One can see that RTA has transformed continuous gold layers into island films that differ in island size and form, as well as coverage of $\mathrm{TiB}_{x}$ surface by metal for the analyzed types of contacts. This may result from differences in the structure (non-uniformities, defects) of $\mathrm{TiB}_{x}$ layers grown in the same conditions but on different substrates ( $\mathrm{Si}$ and GaAs). The situation, however, is somewhat more complicated since Au disperse structure is determined not only by the above factors but also by coalescence of particles. Nevertheless, one may suppose that $\mathrm{TiB}_{x}$ film sputtered onto $\mathrm{Si}$ is more perfect than that on GaAs. In this case bigger Au islands should be observed on GaAs. They can appear on groups of active centers that are close to each other. Such centers may be micropores or micrograin boundaries in the quasi-amorphous films of titanium boride. Further changes in island form depend on the interaction between the islands and substrate. At elevated temperatures the association between the islands and
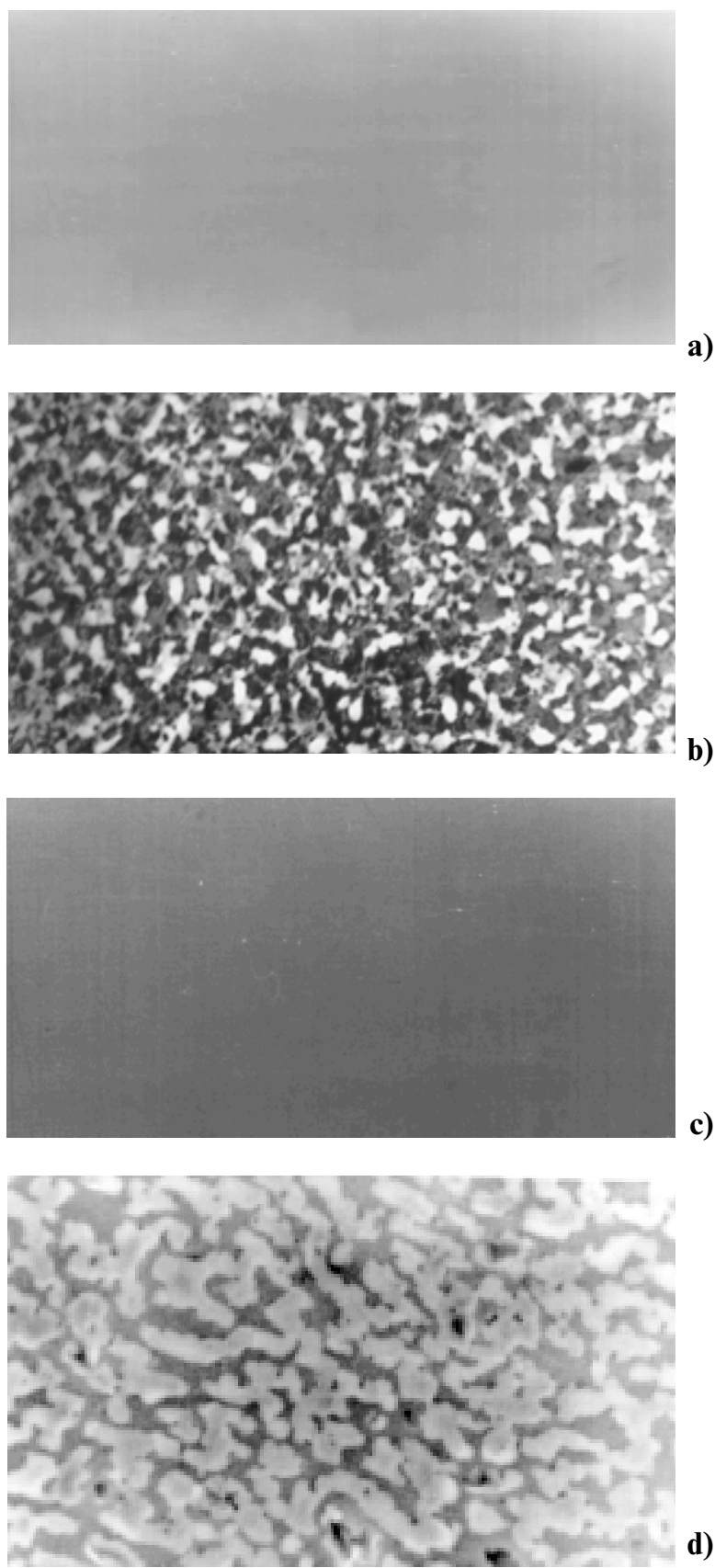

d)

Fig. 7. Morphology of $\mathrm{Si}-\mathrm{TiB}_{x}-\mathrm{Au}(\mathrm{a}, \mathrm{b})$ and $\mathrm{GaAs}-\mathrm{TiB}_{x}-\mathrm{Au}(\mathrm{c}$, d) contact surfaces: a, c - initial (magnification 5000); b, d after RTA at $T=800^{\circ} \mathrm{C}$ (magnification 2000).

substrate becomes weaker. This leads to the islands migration with further coalescence. When there is no interaction between islands and their movement at the surface plane is slow, then each island takes an equilibrium form due to surface tensile forces only. As a result, chains appear in a film made up of such isolated small crystals. The chain form, as was stated earlier, is related to the substrate imperfection.

Short-term technological thermal annealing and presence of defects in the antidiffusion barrier are favorable 


\section{N.S. Boltovets et al.: Technology and experimental studies of contacts for ...}

to penetration of gold atoms to the metal-semiconductor interface and, as a result, catastrophic degradation of the contact electrophysical parameters. The rate of gold penetration could be reduced by adding additional layers with high activation energy of diffusion to the metallization system. Shown in Fig. 8 are the results of our investigations of structural changes in the multilayer Si$\mathrm{Ti}-\mathrm{TiB}_{x}-\mathrm{Mo}-\mathrm{Au}$ contact system due to RTA at $600{ }^{\circ} \mathrm{C}$. Contrary to the $\mathrm{Si}_{-} \mathrm{TiB}_{x}$-Au contacts (cf. Fig. 7), the structures with Mo demonstrate substantial morphological changes in the contact multilayer structure even after RTA at $600{ }^{\circ} \mathrm{C}$.

First, microcracks appear in the $\mathrm{TiB}_{x}$ layer. They seem to be due to relaxation of high intrinsic stresses in it. Indeed, the contact components differ substantially in their coefficients of linear expansion (see Table 1). Therefore stresses in both initial structures and those after RTA have to be rather high. Presence of a thin (about $10 \mathrm{~nm}$ ) Mo interlayer (whose coefficient of linear expansion is close to that of $\mathrm{TiB}_{2}$ ) in the metallization layer seems to be insufficient to provide the required decrease of stresses in the structure studied.

Second, the materials of a thin-film structure can locally interact through their interfaces, and this may result in formation of alloys or intermetallic compounds. Radiography shows that gold and molybdenum do not form intermediate phases under the test conditions. According to [6], solubility of Mo in Au in solid state at RTA at a temperature of $600{ }^{\circ} \mathrm{C}$ is low; the same is true also for solubility of $\mathrm{Au}$ in Mo. Therefore the reaction between Mo and $\mathrm{TiB}_{x}$ may be responsible for local changes in chemical composition of the $\mathrm{TiB}_{x}$ layer. There are

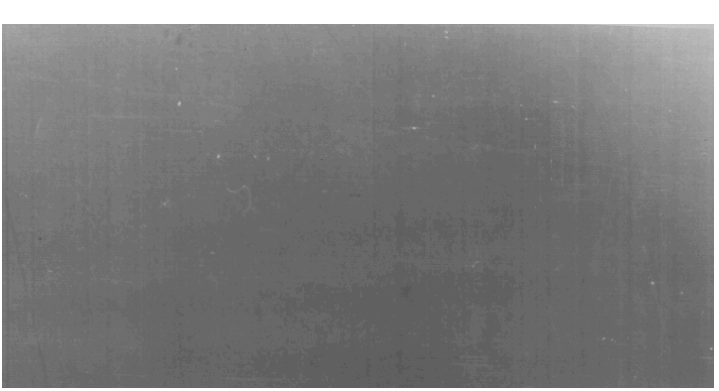

a)

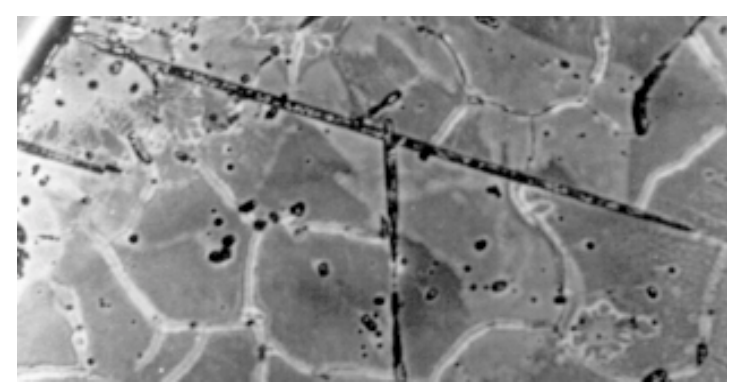

Fig. 8. Morphology of $\mathrm{Si}-\mathrm{Ti}-\mathrm{TiB}_{2}-\mathrm{Mo}-\mathrm{Au}$ contact surfaces: a initial (magnification 5000); b - after RTA at $T=600^{\circ}$ (magnification 2000).
Table 1. Coefficients of linear expansion $\alpha$ for some metals and compounds [5].

\begin{tabular}{l|ccccccc}
\hline \hline Substance & $\mathrm{Au}$ & $\mathrm{Mo}$ & $\mathrm{Ti}$ & $\mathrm{Si}$ & $\mathrm{GaAs}$ & $\mathrm{TiB}_{2}$ & $\mathrm{TiN}$ \\
\hline$\alpha, 10^{-6} \mathrm{~K}^{-1}$ & 14.0 & 5.27 & 1.3 & 2.54 & 5.82 & 5.5 & 4.7 \\
\hline \hline
\end{tabular}

no data on chemical interaction between $\mathrm{Mo}$ and $\mathrm{TiB}_{x}$ in the literature.

Local chemical interactions may occur also at the Si$\mathrm{Ti}$ interface, because the annealing temperature is high enough for titanium silicide formation. It was noted in $[7,8]$ that silicide phases are intensely formed in the diffusion area of $\mathrm{Si}$-Ti contact starting from temperature of about $500{ }^{\circ} \mathrm{C}$. The first of the observed phases is $\mathrm{TiSi}_{2}$ (enthalpy of its formation $\Delta H \approx 10.7 \mathrm{kcal} / \mathrm{gram}$-atom [9], growth kinetics $\sim \sqrt{t}$ and activation energy of the silicide layer growth is about $1.8 \mathrm{eV}$ [10]). Incorporation of this phase in $\mathrm{TiB}_{x}$ layer may promote an increase of the compressing intrinsic stresses [11]. Change of the ratio of diffusant concentrations, presence of oxygen and boron, as well as mechanical stresses, can substantially affect phase formation. This fact prevents one from making a trustworthy estimation of silicide formation in contacts, especially as the enthalpies of possible silicides formation (as could be found from the phase diagrams for binary systems) are close: $\Delta H \approx-17.3 \div-10.7 \mathrm{kcal} / \mathrm{gram}-$ atom $[9,12,13]$.

The above features that result in a decrease of thermal stability for barrier metallization $[14,15]$ may be overcome by replacing the barrier-forming $\mathrm{TiB}_{2}$ layer with TiN. To prove this we investigated contacts of two types, namely, Si-TiN-Au and Si-TiN-Ti-Au. Shown in Fig.9 are the results of our SEM studies of the above contact structures both before and after RTA. Let us first discuss the Si-TiN-Au structure. One can see from Fig. 9 that RTA at $600{ }^{\circ} \mathrm{C}$ results in degradation of the contact structure. This degradation begins in local regions of TiN film and is related to the presence of pores and cracks there. This conclusion is also supported by the results obtained in [15]. The number of the above defects is proportional to mechanical stresses in the barrier layer. These stresses may reach the values that are enough for local exfoliation of TiN film [15]. By varying film structure and thickness one can sometimes make the discussed pair thermally stable up to temperatures $\cong 750{ }^{\circ} \mathrm{C}[15]$.

Let us now discuss another way of increasing thermal stability of a contact structure by incorporating a $\mathrm{Ti}$ sublayer between TiN and Au film. This Ti sublayer improves adhesive strength of $\mathrm{Au}$ layer. (Such way is more convenient from the standpoint of technology.) According to [6], for the solid state Ti solubility in Au is small; formation of intermetallic compounds and eutectic transformations occur at higher temperatures. However, as it follows from Fig. 9, morphological transformations in this structure are practically the same as in the Si-TiNAu contact.

One may suppose that degradation of the Si-TiN-TiAu contact system stems from the same factors as in the 
N.S. Boltovets et al.: Technology and experimental studies of contacts for ...

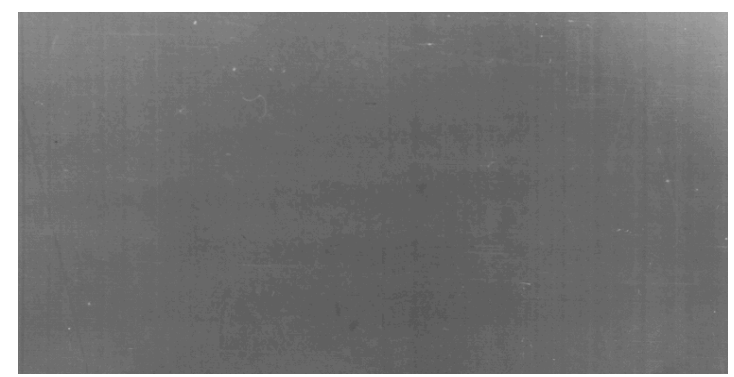

a)

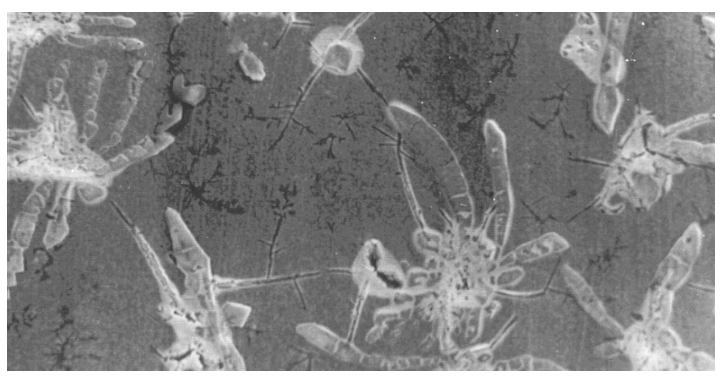

b)

Fig. 9. Morphology of $\mathrm{Si}-\mathrm{TiN}-\mathrm{Au}$ contact surfaces: a - initial (magnification 5000); b - after RTA at $T=600^{\circ} \mathrm{C}$ (magnification 2000).

Si-TiN-Au contact. This is primarily high level of compressive mechanical stresses in TiN layer. These stresses seem to remain even after incorporating a thin $(\sim 20 \mathrm{~nm})$ Ti sublayer into the structure (see Fig. 10).

An additional factor that favors degradation is chemical interactions between the layers that form contact structure. It was noted in [16] that the Ti-Au film pairs are unstable. It was shown that titanium interacts with gold even at a temperature of about $250^{\circ} \mathrm{C}$. It is also known [17] that gold in titanium is an impurity with anomalously fast diffusion. The above factors and their role in degradation processes deserve more careful analysis.

We analyzed possible chemical interactions in the contact layer structure by taking concentration depth profiles (AES plus layer-by-layer etching). Shown in Fig. 11 are such profiles for the components of $\mathrm{Si}^{-\mathrm{TiB}_{x}}$ contact structure. These profiles reflect the features of inter-phase interactions in the contact at different annealing temperatures. One can see that barrier properties of the $\mathrm{TiB}_{x}$ layer retain even up to $600{ }^{\circ} \mathrm{C}$. The antidiffusion layer fails during annealing at $800{ }^{\circ} \mathrm{C}$; after this it is no longer an obstacle to both the flow of silicon atoms to the $\mathrm{TiB}_{x}$ film surface and their chemical interaction with the film components and oxygen. Deposition of a gold film does not have a pronounced effect on the transformation of inter-phase interactions in the contact. Both the barrier properties and chemical composition of the $\mathrm{TiB}_{x}$ layer retain after RTA at $600{ }^{\circ} \mathrm{C}$, but at $800{ }^{\circ} \mathrm{C}$ the barrier layer is completely decomposed. One may suppose that this process is based on the interaction between silicon and titanium that is enhanced by the eutectic-type reactions, such as between silicon and gold or titanium silicide and gold. These reactions start in small

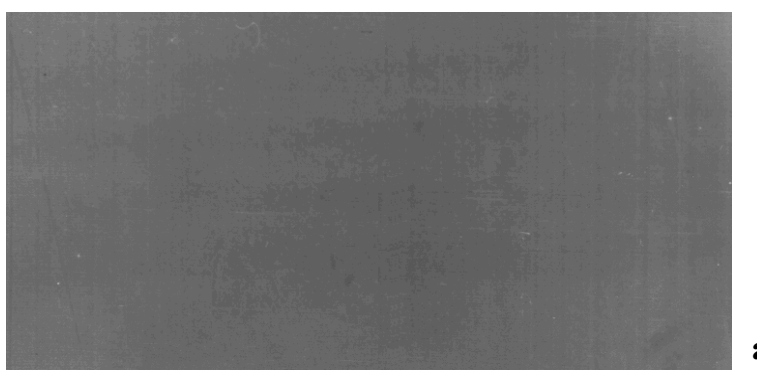

a)

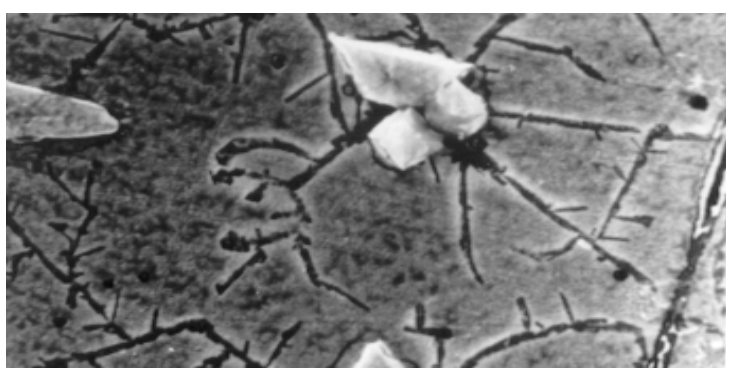

b)

Fig. 10. Morphology of $\mathrm{Si}-\mathrm{TiN}-\mathrm{Ti}-\mathrm{Au}$ contact surfaces: a - initial (magnification 5000); $\mathrm{b}-$ after RTA at $T=600^{\circ} \mathrm{C}$ (magnification 2000).

local areas at both $\mathrm{Si}_{-} \mathrm{TiB}_{x}$ and $\mathrm{TiB}_{x}-\mathrm{Au}$ interfaces. A possibility of chemical reactions between silicon and titanium at the above temperatures seems to be beyond doubt. As to the interaction between gold and titanium, we would like to refer to [18]. In that work TiAu and $\mathrm{TiAu}_{2}$ compounds have been detected after thermal annealing at as low temperatures as about $350{ }^{\circ} \mathrm{C}$. Obviously, the rate of diffusion for the contact structure components substantially increases in this case.

The discussed mechanisms for degradation in contact structures with antidiffusion barriers based on $\mathrm{TiB}_{x}$ were confirmed by the results of investigations of structures with additional Mo and Ti layers: $\mathrm{Au}-\mathrm{Mo}-\mathrm{TiB}_{2}-\mathrm{Si}$ and $\mathrm{Au}-\mathrm{Mo}-\mathrm{TiB}_{2}-\mathrm{Ti}-\mathrm{Si}$ (see Fig.12). Low Au solubility in Mo makes it possible to somewhat reduce Au penetration into the antidiffusion layer and disruption of the latter. However, the factors retain that provide chemical interaction at the semiconductor boundary, so the layer structure of the contact still will degrade. Incorporation of a thin Ti film, of course, does not radically affect thermal stability of the contact structure; this operation, however, improves adhesion of the $\mathrm{TiB}_{x}$ layer due to deoxidation of silicon surface and also somewhat increases thermal stability because it serves to localize the areas of $\mathrm{TiB}_{x}$ layer where chemical reactions occur. The character of atomic intermixing at $800^{\circ} \mathrm{C}$ for the contact structure with an additional Ti sublayer at the Si boundary differs from that for the contact structure without such sublayer.

In principle, all the above compounds might serve as barrier layers for microwave diodes. When using barrier layers in a specific contact system, it is necessary to apply such technological procedures that provide sufficiently high purity of the elemental composition for the 
N.S. Boltovets et al.: Technology and experimental studies of contacts for ...

a)

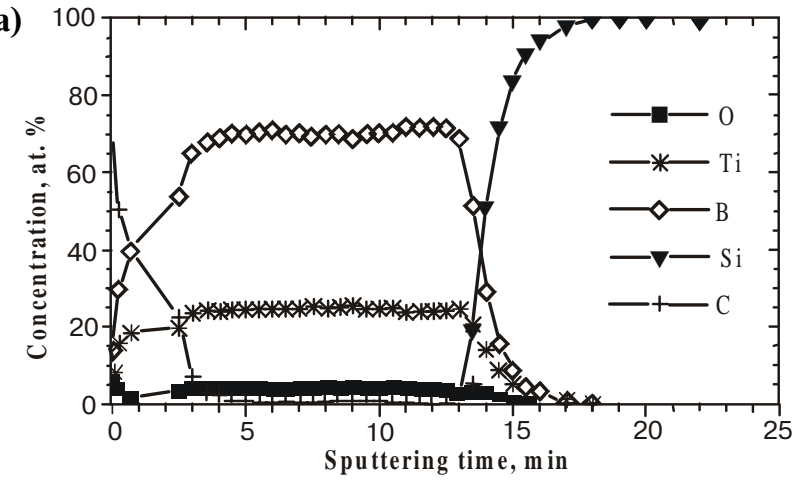

c)

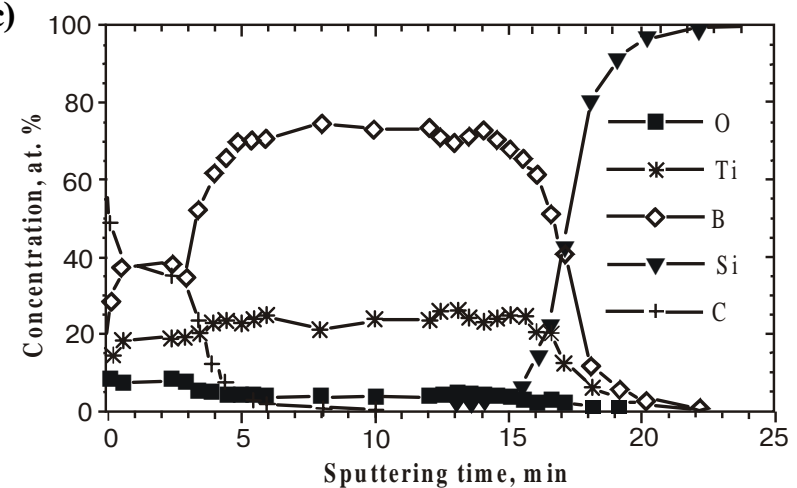

b)

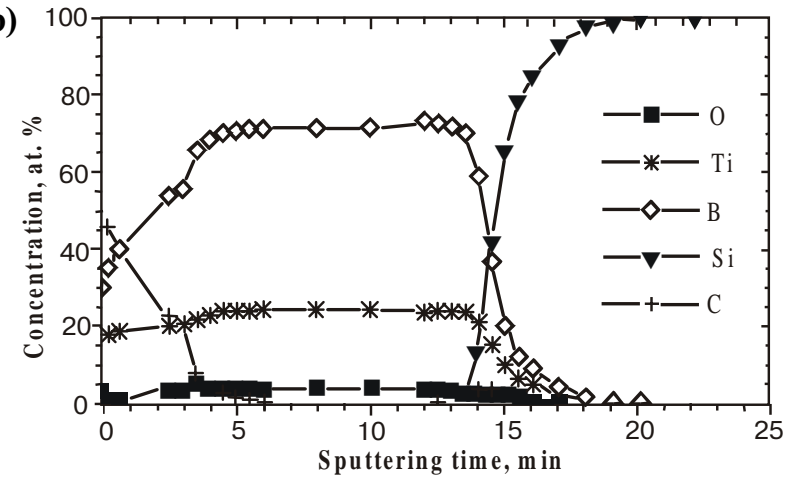

d)

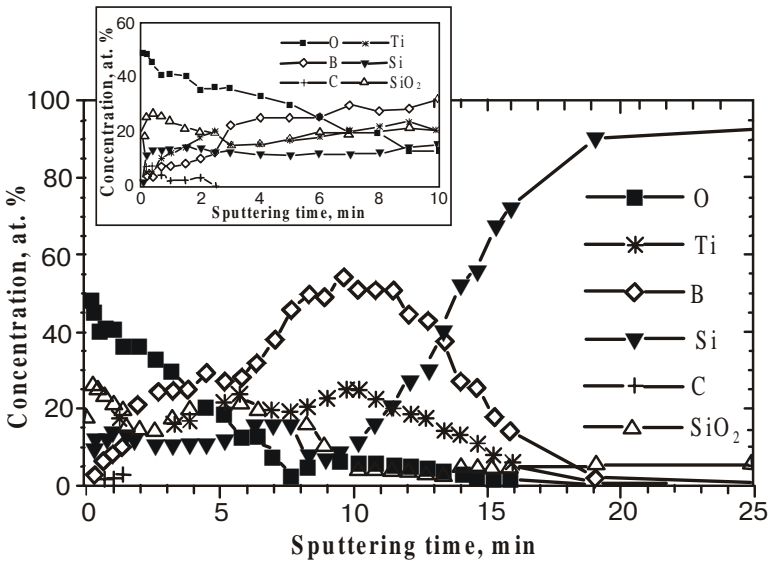

Fig. 11. Concentration depth profiles for the $\mathrm{TiB}_{x}$-Si contact components: a - initial (before annealing); b, c, d (e)- after RTA at $T=$ 400,600 and $800{ }^{\circ} \mathrm{C}$.
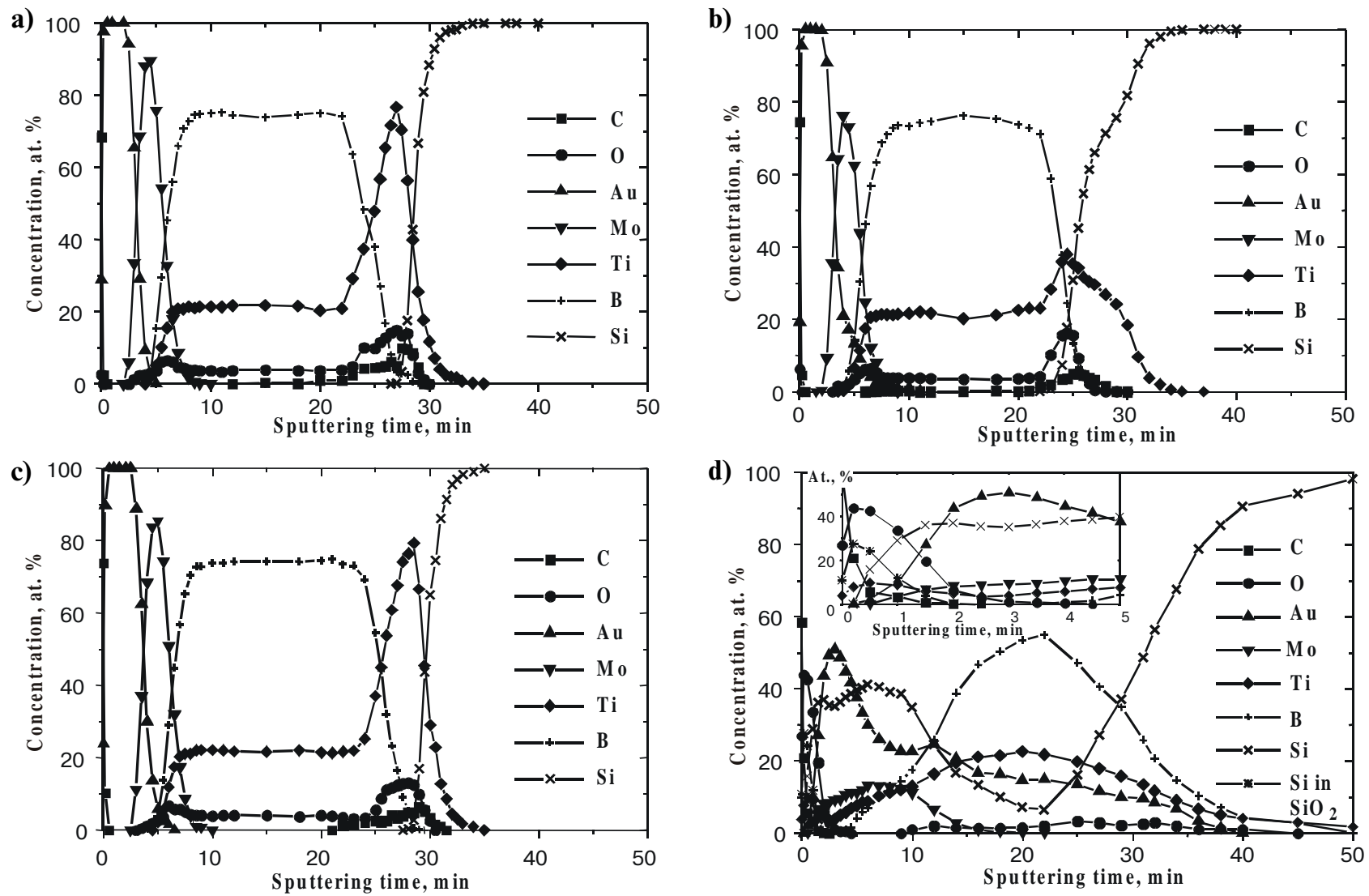

Fig. 12. Concentration depth profiles for the $\mathrm{Au}-\mathrm{Mo}-\mathrm{TiB}_{x}-\mathrm{Ti}-\mathrm{Si}$ contact components: a - initial (before annealing); b, c, d - after RTA at $T=400,600$ and $800{ }^{\circ} \mathrm{C}$. 
N.S. Boltovets et al.: Technology and experimental studies of contacts for ...

Table 2. Contact resistance $R_{c}\left[\Omega \cdot \mathrm{cm}^{2}\right]$ of $\mathrm{Au}-\mathrm{TiB}_{2}-\mathrm{Si}, \mathrm{Au}-\mathrm{TiB}_{2}-\mathrm{Ti}-\mathrm{Si}$ and $\mathrm{Au}-\mathrm{Mo}-\mathrm{TiB}_{2}-\mathrm{Ti}-\mathrm{Si}$ structures before and after $\mathrm{RTA}(60 \mathrm{~s})$.

\begin{tabular}{l|c|c|c|c}
\hline \hline \multirow{2}{*}{ Type of contacts } & \multicolumn{3}{|c}{ Annealing temperature } \\
\cline { 2 - 5 } & before RTA & $400^{\circ} \mathrm{C}$ & $600^{\circ} \mathrm{C}$ & $800^{\circ} \mathrm{C}$ \\
\hline $\mathrm{Au}-\mathrm{TiB}_{2}-n^{+}-\mathrm{Si}$ & $2 \times 10^{-4}$ & $2 \times 10^{-4}$ & $8 \times 10^{-5}$ & $1 \times 10^{-4}$ \\
\hline $\mathrm{Au}-\mathrm{TiB}_{2}-\mathrm{Ti}-n^{+}-\mathrm{Si}$ & $2.1 \times 10^{-6}$ & $2.1 \times 10^{-6}$ & $1.3 \times 10^{-6}$ & $8 \times 10^{-6}$ \\
\hline $\mathrm{Au}-\mathrm{Mo}-\mathrm{TiB}_{2}-\mathrm{Ti}-n^{+}-\mathrm{Si}$ & $2.1 \times 10^{-6}$ & $2.1 \times 10^{-6}$ & $\sim 1.5 \times 10^{-6}$ & $5 \times 10^{-6}$ \\
\hline \hline
\end{tabular}

barrier layer, low $(\rho<100 \mu \Omega \cdot \mathrm{cm})$ resistivity and good adhesion of the barrier layer to the near-contact and outer regions of contact systems, as well as minimal thermomechanical stresses in diode structures.

\section{Electrophysical parameters of contact systems}

Investigations of contacts to silicon diode structures were performed on wafers that served both as substrates to epitaxially grow the active areas for microwave diode structures and one of the main design components. Standard wafers were used whose resistivity was $0.003 \Omega \cdot \mathrm{cm}$ (concentration of donors $N_{D}=2 \cdot 10^{19} \mathrm{~cm}^{-3}$ ). We also investigated the test Schottky barrier diode structures based on silicon and gallium arsenide epitaxial $n-n^{+}$structures with thin boride and nitride layers as barriers. To perform measurements at low frequencies, the test samples were fabricated as forward mesas on the wafer. We made also test structures as the diode chips; they were mounted in high-frequency packages. The measurements for these samples were made in the $1 \mathrm{MHz}$ to $12 \mathrm{GHz}$ frequency range and in the temperature range typical for operation of the contact systems. We studied the $I-V$ curves and contact resistivity in the current density range from 1 to $10^{4} \mathrm{~A} / \mathrm{cm}^{2}$.

The contact resistivity was measured using techniques from [4]. It dropped over the whole current density range when temperature increased; its frequency dependence in the $1 \mathrm{MHz}$ to $12 \mathrm{GHz}$ frequency range was but slight. A trend was found toward resistivity decrease with frequency.

We studied thermal stability of ohmic contacts to the silicon and gallium arsenide contact structures. Typical values of the contact resistivity before and after RTA for $\mathrm{Si}-n^{+}-\mathrm{TiB}_{2}-\mathrm{Au}, \mathrm{Si}-n^{+}-\mathrm{Ti}-\mathrm{TiB}_{2}-\mathrm{Au}$ and $\mathrm{Si}-n^{+}-\mathrm{Ti}_{-} \mathrm{TiB}_{2-}$ Mo-Au structures are given in Table 2. The above contact structures are rather stable under RTA at temperatures from 400 up to $600^{\circ} \mathrm{C}$. But their parameters strongly degrade at a temperature of $800{ }^{\circ} \mathrm{C}$.

We investigated also electrophysical characteristics of the Schottky barrier diode structures for $\mathrm{TiN}_{x}-\mathrm{Si}, \mathrm{TiN}_{x^{-}}$ GaAs, $\mathrm{NbN}_{x}-\mathrm{Si}, \mathrm{NbN}_{x}$-GaAs, $\mathrm{ZrB}_{x}-\mathrm{Si}, \mathrm{ZrB}_{x}-\mathrm{GaAs}$. Exposition to ${ }^{60} \mathrm{Co} \gamma$-radiation in the $10^{5}-10^{7}$ rad dose range improves the Schottky barrier characteristics: its spread drops. The results obtained may be explained according to the model for interaction of metal-semicon- ductor heterostructures with low doses of $\gamma$-radiation that has been developed by the authors - see [19-22]. This result may be of undeniable interest for Schottky barrier diode manufacturing technology.

Thermal stability of the electrophysical parameters of contact systems was studied for the Schottky barrier test structures. The parameters were measured both before and after RTA for $60 \mathrm{~s}$ in the inert gas at temperatures of $400,600,800$ and $950{ }^{\circ} \mathrm{C}$. They are given in Table 3.

Practically for all the structures studied RTA at $400{ }^{\circ} \mathrm{C}$ improved the Schottky barrier parameters. After RTA at $600{ }^{\circ} \mathrm{C}$ in most cases the parameters became almost the same as those for initial (non-annealed) structures. For some structures the reverse current increased. This might result from surface processes in the test structures. RTA at $800^{\circ} \mathrm{C}$ led to a considerable degradation of the Schottky barrier parameters for most of systems. It should be noted that the diode characteristics remained the same; degradation of parameters meant an increase of both reverse current and ideality factor.

The results obtained agree well with morphology of the $\mathrm{TiB}_{x}$-Si and $\mathrm{TiB}_{x}-\mathrm{GaAs}$ interfaces (Figs 13 and 14) and distribution of non-uniformities at them before and after RTA at $T=400$ and $600{ }^{\circ} \mathrm{C}$. The morphological studies were made with an atomic force microscope Dimension 3000 after the $\mathrm{Au}$ and $\mathrm{TiB}_{x}$ metallization layers have been removed by ion etching. The scanned area was $5 \times 5 \mu \mathrm{m}^{2}$.

\section{Reliability of silicon oscillator microwave diodes with ohmic contacts based on interstitial phases}

We studied reliability of the silicon IMPATT diodes with ohmic contacts based on interstitial phases. The structure of $p-n$ junction was that proposed for realization of the INCO-COPERNICUS Project No 977131 «MEMSWAVE». The diodes were exposed to accelerated tests in a forced mode. These tests have shown that the activation energy for diode degradation process was $E_{a}=2.03 \mathrm{eV}$. The median value of the mean time between failures (MTBF) at temperatures of 250,220 and $200{ }^{\circ} \mathrm{C}$ was $5.6 \cdot 10^{5}, 3.4 \cdot 10^{6}$ and $2.4 \cdot 10^{7} \mathrm{~h}$, respectively.

When processing the results of accelerated tests at elevated temperatures, it was found that failure distribution obeyed the logarithmic normal law. The only mecha- 
N.S. Boltovets et al.: Technology and experimental studies of contacts for ...
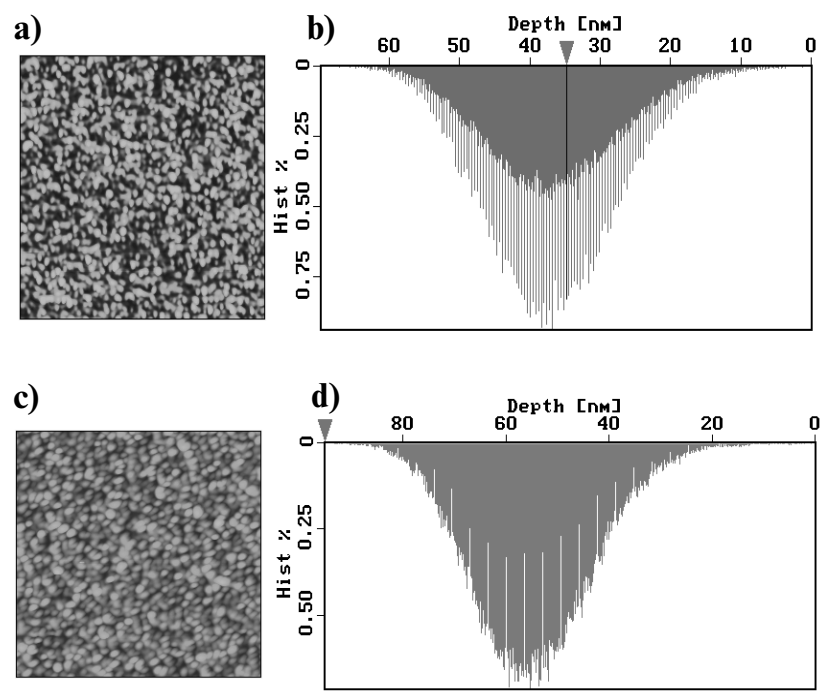

e)

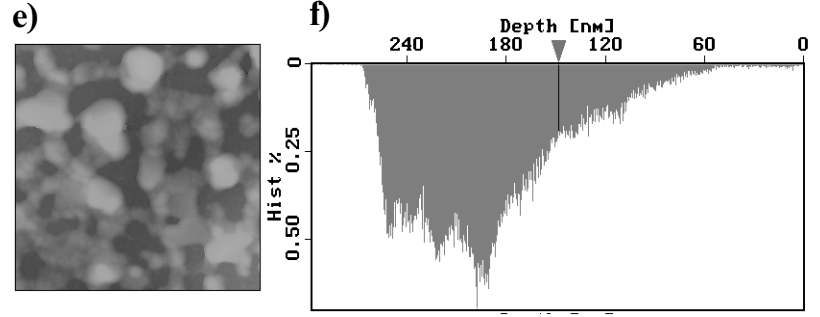

Fig. 13. GaAs surface morphology (a, c, e) and histogram of $\mathrm{GaAs}$ surface irregularities after removal of $\mathrm{Au}^{-\mathrm{TiB}_{x}}$ layers $(\mathrm{b}$, d, f): a, b - initial; c, d (e, f) - after RTA at $400(600){ }^{\circ} \mathrm{C}$.

nism for failures that was observed was the mesa penetration. The total fraction of failures during time $t$ at a temperature $T$ is determined from the following expression:

$$
P(t, T)=\operatorname{gauss}\left[\left(\ln t-\ln t_{50}+E_{a} / k T\right) / \sigma\right] .
$$

Here $\sigma$ is the standard deviation of the logarithm of time:
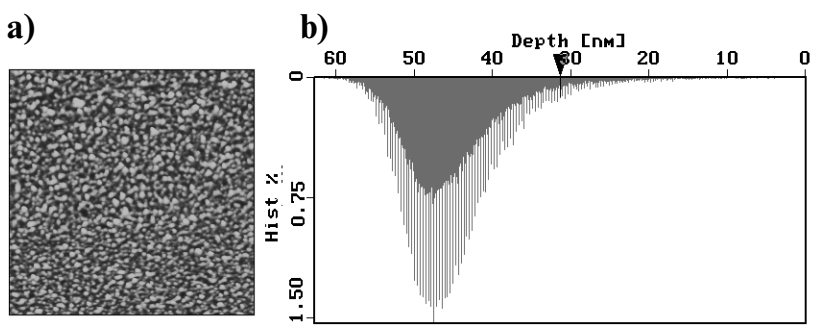

c)
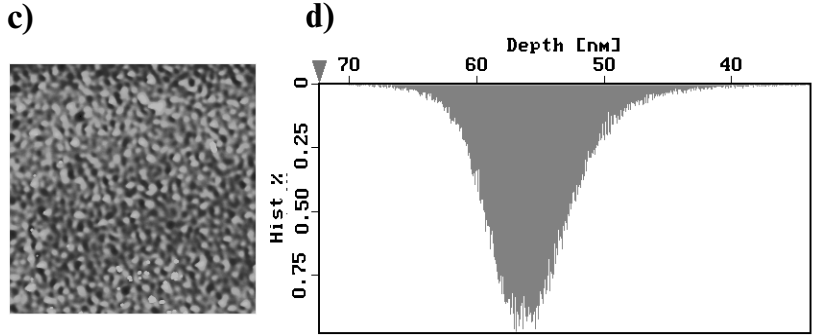

e)

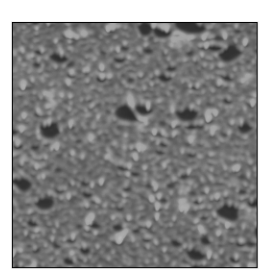

f)

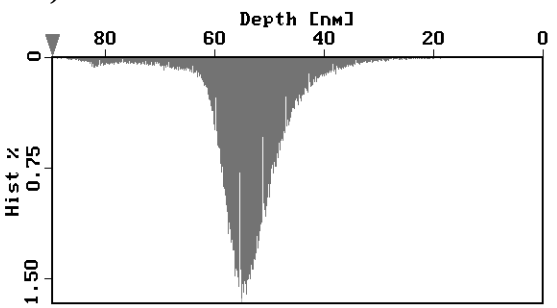

Fig. 14. Si surface morphology (a, c, e) and histogram of $\mathrm{Si}$ surface irregularities after removal of $\mathrm{Au}-\mathrm{TiB}_{x}$ layers $(\mathrm{b}, \mathrm{d}, \mathrm{f})$ : a, b - initial; c, d (e, f) - after RTA at 400 (600) ${ }^{\circ} \mathrm{C}$.

$\sigma=\ln t_{50}-\ln t_{84} ; t_{84}$ is time to $16 \%$ failures; gauss is the normal Gaussian. The temperature of the $p-n$ junction was $335^{\circ} \mathrm{C}$; for this temperature $\sigma=2.4$. For contacts with palladium metallization exposed to the same tests $s$ $=0.91$, while the activation energy for diode degradation process was $E_{a}=0.9 \mathrm{eV}$; for contacts with platinum

Table 3. The Schottky barrier parameters (barrier height $\varphi_{B}$ and ideality factor $n$ ) of different contacts based on interstitial phases before and after RTA (60 s).

\begin{tabular}{|c|c|c|c|c|c|c|c|c|c|}
\hline \multirow{3}{*}{$\begin{array}{c}\text { Type } \\
\text { of contacts }\end{array}$} & \multicolumn{9}{|c|}{ Annealing temperature } \\
\hline & \multicolumn{2}{|c|}{ before RTA } & \multicolumn{2}{|c|}{$400^{\circ} \mathrm{C}$} & \multicolumn{2}{|c|}{$600^{\circ} \mathrm{C}$} & \multicolumn{2}{|c|}{$800^{\circ} \mathrm{C}$} & $950^{\circ} \mathrm{C}$ \\
\hline & $\varphi_{\mathrm{B}}, \mathrm{eV}$ & $n$ & $\varphi_{\mathrm{B}}, \mathrm{eV}$ & $n$ & $\varphi_{\mathrm{B}}, \mathrm{eV}$ & $n$ & $\varphi_{\mathrm{B}}, \mathrm{eV}$ & $n$ & $\varphi_{\mathrm{B}}, \mathrm{eV} \quad n$ \\
\hline $\mathrm{TiN}_{x}-n-n^{+}-\mathrm{Si}$ & 0.59 & 1.36 & 0.58 & 1.11 & 0.57 & 1.27 & 0.53 & 1.51 & \\
\hline $\mathrm{NbN}_{x}-n-n^{+}-\mathrm{Si}$ & 0.56 & 1.1 & 0.56 & 1.1 & 0.56 & 1.18 & 0.56 & 1.3 & \\
\hline $\mathrm{TiB}_{x}-n-n^{+}-\mathrm{Si}$ & 0.55 & 1.1 & 0.57 & 1.09 & 0.59 & 1.24 & 0.58 & 1.47 & \\
\hline $\mathrm{ZrB}_{x}-n-n^{+}-\mathrm{Si}$ & 0.52 & 1.08 & 0.55 & 1.06 & 0.55 & 1.1 & 0.55 & 1.2 & 0.57 \\
\hline $\mathrm{TiN}_{x}-n-n^{+}-\mathrm{GaAs}$ & 0.59 & 1.06 & 0.60 & 1.05 & 0.66 & 1.08 & 0.78 & 1.1 & 0.78 \\
\hline $\mathrm{NbN}_{x}-n-n^{+}-\mathrm{GaAs}$ & 0.68 & 1.12 & 0.70 & 1.08 & 0.68 & 1.3 & 0.65 & 1.28 & 0.65 \\
\hline $\mathrm{TiB}_{x}-n-n^{+}-\mathrm{GaAs}$ & 0.78 & 1.3 & 0.74 & 1.17 & 0.78 & 1.13 & 0.65 & 1.4 & \\
\hline $\mathrm{ZrB}_{x}-n-n^{+}-\mathrm{GaAs}$ & 0.70 & 1.1 & 0.72 & 1.08 & 0.70 & 1.1 & 0.65 & 1.3 & \\
\hline
\end{tabular}




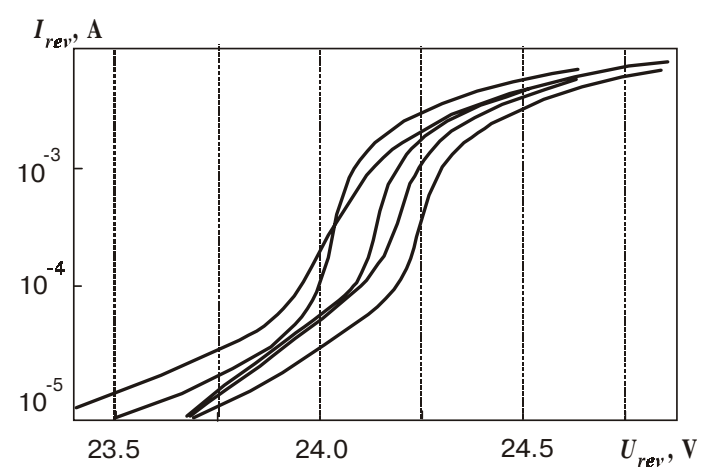

$d I / d U$
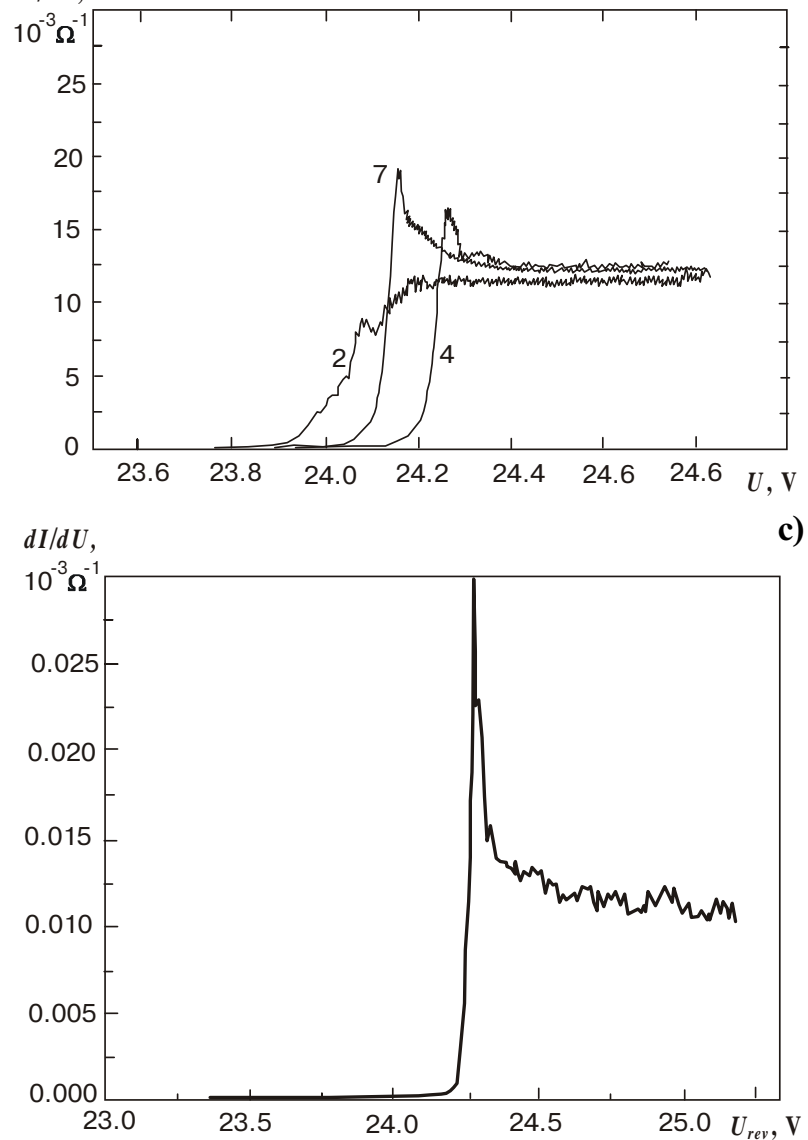

Fig.15. $I-V$ curves of IMPATT diode (a) and their first derivatives in the region of developed avalanche breakdown (b); typical manifestation of a microplasma on the first derivative curve (c).

metallization the corresponding values were $1.2(\sigma)$ and $1.3 \mathrm{eV}\left(E_{a}\right)$

It was also found that the reason for mesa penetration was the bulk non-uniformity of semiconductor that resulted in a current pinch [23]. One can observe a weakly pronounced kink on the $I-V$ curves that practically cannot be detected by standard curve tracers. It is, however, well pronounced on the curves for the first and second derivatives of the $I-V$ curves.

a)
Using an automated diagnostic system and some techniques developed by us [24], we have found a correlation between the features of the first and second derivatives of the $I-V$ curves and time to failure for diodes. Some diodes had a microplasma whose voltage was 40 to $80 \mathrm{mV}$ less than the diode avalanche breakdown voltage. It is such a microplasma that practically cannot be detected on the static $I-V$ curve; it can be detected by differentiating the $I-V$ curve. The resistance of a microplasma changes from sample to sample but slightly; it is about $3 \mathrm{k} \Omega$. This fact evidences that the current pinches are of the same diameter. A theoretical estimation gives for this diameter a value of $1-3 \mu \mathrm{m}$. Typical $I-V$ curves at the avalanche region are presented in Fig. 15a, while their derivatives are given in Fig. 15b. The distinctive features of a microplasma on the curve for the first derivative are shown in Fig. 15c. One can see that the diode differential resistance has increased.

An analysis of catastrophic failures (with mesa penetration) has shown that diameter of the penetration area corresponds to the value of the current pinch diameter and is $1-2 \mu \mathrm{m}$. The same size of penetration area was observed after operational failures [23]. This fact may serve as evidence that catastrophic failures of IMPATT diodes at forced tests and during operation are identical.

No parametric failures were observed for IMPATT diodes with the ohmic contact metallization based on $\mathrm{Pd}_{2} \mathrm{Si}$, TiN or TiB $x$ films, be it contact to $p^{+}-\mathrm{Si}$ or $n^{+}-\mathrm{Si}$. Such failures are typical for standard metallization and are related to transport of metal and semiconductor atoms in contacts. RTA at $T=400,500{ }^{\circ} \mathrm{C}$ for $60 \mathrm{~s}$ in hydrogen atmosphere did not change metallization parameters and diode electrical characteristics. Thermal annealing of diode structures at $T=400(500){ }^{\circ} \mathrm{C}$ for 2 (1) $\mathrm{h}$ in vacuum also did not lead to any changes of both the contacts and their $I-V$ curves.

\section{Conclusions}

We developed methods for magnetron sputtering of titanium nitrides and borides and zirconium borides from powder targets, as well as reactive thermal sputtering of titanium nitrides, onto silicon and gallium arsenide substrates.

The quasi-amorphous structure of sputtered coatings was tested for service as contacts to silicon and gallium arsenide substrates. The investigations of electrophysical parameters have shown that all the contact systems studied were rather stable at rapid thermal annealing up to a temperature of $600{ }^{\circ} \mathrm{C}$ and exposition to ${ }^{60} \mathrm{Co} \gamma$-radiation in the $10^{4}-10^{7}$ rad dose range.

Comprehensive studies of the evolution of contact systems with antidiffusion $\mathrm{TiN}$ and barrier $\mathrm{Pd}_{2} \mathrm{Si}$ layers at elevated temperatures and analysis of diode parameters during bench tests demonstrated that it is possible to make silicon double-drift IMPATT diodes of improved reliability (the mean time between failures was $2.4 \cdot 10^{7} \mathrm{~h}$ at a temperature of $200^{\circ} \mathrm{C}$ ). 


\section{N.S. Boltovets et al.: Technology and experimental studies of contacts for ...}

\section{Acknowledgement}

This work was supported by the INCO-COPERNICUS Program (Project No 977131 «MEMSWAVE»).

\section{References}

1. Thin Films: Interdiffusion and Reactions, Eds. J.M. Poate, K.N. Tu, J.W. Mayer, Wiley-Interscience Publ. John Wiley and Sons, New York-Chichester-Brisbane-Toronto-Singapore (1978).

2. M.A. Nicolet, Diffusion barrier in thin films // Thin Solid Films 52, pp. 415-443 (1978).

3. K. Gershinsky, A.V. Rzhanov, E.I. Cherenov, Thin film silicides in electronics (in Russian) // Mikroelektronika 11(2), pp. 83-94 (1982).

4. M. Shur, GaAs Devices and Circuits, Plenum Press, New YorkLondon (1987)

5. Physical Values: Handbook (in Russian), Eds. I.S. Grigoriev, E.S. Meilikhov, Energoatomizdat, Moscow (1991).

6. M. Hansen, R. Anderko, Constitution of Binary Alloys, v I, II, McGraw-Hill, New York-Toronto-London (1958).

7. L.S. Hung, J. Gyulai, J.W. Mayer, S.S. Lau, M.A. Nicolet // J. Appl. Phys. 54(9), pp. 5076-5080 (1983).

8. Youn Tac Kim, Chi-Hoon Sun, Sin Ho Lee, Song Tae Back, Hyung Souh Yoo // J. Vac. Sci. Technol. A14(6), pp. 32453251 (1996).

9. S.P. Murarca, Silicides for VLSI Application, Academic Press, New York-London-Paris (1983).

10. G.G. Ottoviani // Mat. Reg. Soc. Symp. 16, pp. 21-31 (1975).

11. E. Zsoldos, G. Peto, V. Sohillet, G. Valyi // Thin Solid Films 137, pp. 243-245 (1986).

12. F.M. Heurle, E.A. Itens, Y.A. Ting // Appl. Phys. Lett. 42(4), pp. 361-363 (1983).
13. R. Pretorius, J.M. Harris, M.A. Nicolet // Solid State Electronics 21, pp. 667-675 (1978).

14. M. Wittmer // J. Vac. Sci. Technol. A2(2), pp. 273-280 (1984)

15. J. Suni, M. Maenpaa, M.A. Nicolet, M. Luomajaw // J. Electrochem. Soc.: Solid State Science and Technology 130(8), pp. 1215-1218 (1983)

16. R.S. Howicki, M.A. Nicolet // Thin Solid Films 96(3) pp. $317-$ 326 (1982).

17. Rare Earth Compounds (in Russian), Nauka, Moscow (1983).

18. N. Cheng, H. Von Seeteld, M.A. Nicolet, In: Proc. Symposium on Thin Film Interfaces and Interactions, Thin Solid Films 80(2), pp. 323-337 (1980).

19. J. Breza, M. Kadlecikova, R.V. Konakova, V.G. Lyapin, V.V. Milenin, V.A. Statov, Yu.A. Tkhorik, M.Yu. Filatov, Radiation processing of $\mathrm{Cr}-\mathrm{GaAs}$ contacts // Appl. Phys. Letters. 67(10) pp.1462-1464 (1995).

20. L.S. Kleinfeld, R.V. Konakova, V.F. Sinkevich, A.A. Pavlenko, The influence of radiation-stimulated gettering on the reliability of structures // J. Electrical Eng. 44(6) pp. 177-178 (1993).

21. A.E. Belyaev, J. Breza, E.F. Venger, M. Vesely, I.Yu. Il'in, R.V. Konakova, J. Liday, V.G. Lyapin, V.V. Milenin, I.V. Prokopenko, Yu.A. Tkhorik, Radiation Resistance of GaAsbased Microwave Schottky-barrier Devices (Some physicotechnological aspects), Interpress Ltd., Kiev (1998).

22. N.S. Boltovets, R.V. Konakova, V.A. Krivutsa, E.A. Soloviev, M.B. Tagaev, Effect of $\gamma$-radiation on the electrophysical parameters of silicon $p-i-n$ diodes (in Russian) // Voprosy Atomnoi Nauki i Tekhniki, Nos 3(69)/4(70), pp. 48-50 (1998).

23. N.S. Boltovets, V.V. Basanets, A.V. Tsvir, A.M. Kurakin, E.F. Venger, R.V. Konakova, V.F. Mitin, E.A. Soloviev, Silicon IMPATT diodes of improved reliability, In: Proc. $10^{\text {th }}$ International Crimean Conference "Microwave \& Telecommunication Technologies» CriMiCo'2000, 11-15 September 2000, pp. 139-140. 